\title{
Statistical Analysis and Determination of Representative Size for Sediment in Malaysian Urban Drains
}

\author{
Charles Hin Joo Bong* \\ Department of Civil Engineering, Faculty of Engineering, Universiti Malaysia Sarawak, \\ 94300, Kota Samarahan, Sarawak, Malaysia
}

\begin{abstract}
This paper highlights the statistical analysis done on sediment samples collected from concrete drains in Malaysian major urban areas in order to understand the characteristics of the sediment and also to determine the suitable representative grain size. Samples were collected from 12 urban areas in Peninsular Malaysia and 1 urban area in East Malaysia and subjected to sieve analysis. Results from sieve analysis had shown that the major component of the sediment was sand with a mean value of $72.2 \%$, followed by gravel with a mean of $24.7 \%$ and silt and clay with a mean of $3.1 \%$. Samples from 10 locations have shown a non normal distribution with the tenderness to skew to the right. Due to this, the conventional use of median grain size, $d_{50}$ as the effective size for sediment samples might not be a good representation for the sediment distribution. Further statistical analysis in this paper have suggested that the mode grain size is a much better representative grain size due to its stability when compared to median and mean size. Thus, a much better representative for the sediment samples from Malaysian urban areas would be the mode size (in this case is $d_{20}$ ).
\end{abstract}

Keywords: Concrete drain, representative size, sediment, urban areas

\section{Introduction}

Sediments commonly found in urban drains consist of particles of differing size, shape and specific gravity. Due to this, it is difficult to choose an effective grain size that is the most representative of the average particle size in the sediment sample distribution. Conventionally, the median diameter $d_{50}$ has been assumed as the size that represents the sediment mixtures. The median diameter $d_{50}$ has been used in the development of equations for incipient motion [1-4]. However, in using these equations at fields, the results were not satisfactory due to the different conditions compared to the controlled condition in the laboratory where the equations were developed suggesting a revision of these equations are needed [5]. This could be partly due to the sediment distribution used in the development of these equations were of uniform grain size with almost lognormal distribution; thus the median diameter, $d_{50}$ is a suitable representation of the sediment since it coincide with the mode and geometric means of the distribution.

Available literatures by various authors have shown that grain size distribution for sediment deposits is not lognormal and tends to skew. It was found that for many fluvial gravel deposits, it tends to skew towards the finer particles (negatively skewed) [6-7]. An analysis of the data from 125 gravel-bed streams mostly from the United States with unimodal distribution have suggested in using

\footnotetext{
* Corresponding author. Tel.: +60-82-583294; fax: +60-82-583410

E-mail address: bhjcharles@unimas.my

Manuscript History:

Received 14 September, 2018, Revised 24 September, 2018, Accepted 26 September, 2018, Published 30 September, 2018
}

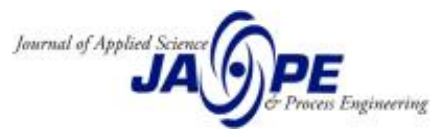


the mode value of $68.8 \%$ or close to $d_{70}$ to be a suitable representation of the sediment distribution [8]. As for urban drain, a study on the sediment distribution collected from 5 residential areas in Kuwait has shown that the distribution tends to skew to the coarser particle (for unimodal distribution) with a mode size of $0.3 \mathrm{~mm}$ and mode percentage value ranging from $11 \%$ to $33 \%$ [9]. The suggestion that mode as being useful in studying sediment mixture is based on the basis that mode is a less bias statistical parameter since it always represents the highest percentage of particles by weight and covers the largest portion when compared to any other size class.

This paper highlights the statistical analysis done on the non-cohesive sediment distributions commonly found in Malaysian urban drains so as to determine the representative particle size of the sediment. A comparison has also been made on the sediment distributions to determine the similarity in terms of characteristics and constituent for the sediments collected from major urban areas in Malaysia. Sediment samples have been collected from 12 major urban areas in Peninsular Malaysia and 1 major urban area in East Malaysia and were subjected to sieve analysis. The results from sieve analysis were then analyzed and discussed further in this paper.

\section{Methodology}

Sediment samples were collected by grab sampling using scoop from urban concrete drains for 12 major urban areas in Peninsular Malaysia namely Bandar Kangar, Alor Setar, Butterworth and Ipoh for Northern Region; Kuala Lumpur, Shah Alam, Seremban and Melaka for Central Region; Johor Bahru for Southern Region and Kuantan, Kuala Terengganu and Kota Bahru for Eastern Region. As for the 1 urban area from East Malaysia; Kuching which is the state capital of Sarawak was chosen and sediment samples from 3 different land developments (residential, commercial and industrial) were taken (see Figure 1); making altogether 15 locations (including the 12 locations in Peninsular Malaysia) where sediment samples were taken for this study. All the samples were oven dried to a temperature of $100 \pm 5^{\circ} \mathrm{C}$ for at least 24 hours. Samples were then broken up into individual particles using pestle and mortar and any impurity like plastics, plant material and glass were removed. Each sample was then mixed thoroughly before weighted and placed in sieve shaker. The sieve sizes used were $20,14,10,5,2.36,1.18,0.6,0.425,0.3,0.212,0.15,0.075 \mathrm{~mm}$ and a pan at the bottom. The sieves were vibrated for 10 minutes. The amount of sediment particles retained on each sieve was weighted and the percentages retained and passed from each sieve were calculated.

From the sieve analysis data, cumulative grain-size distribution, showing the percentage passing against diameter size was plotted on a semi-logarithmic for each of the sediment samples. The system of classification used was based on the system recommended by the American Geophysical Union. Under this system, anything having a size larger than $2 \mathrm{~mm}$ is considered to be gravel; sand having a size limit of below $2 \mathrm{~mm}$ but larger than $0.062 \mathrm{~mm}$ while silt and clay is considered to have size smaller than $0.062 \mathrm{~mm}$. To check the 'skewness' or the deviation from normal for the distribution, a histogram of percentage retained against particle size diameter was plotted for each of the samples. 


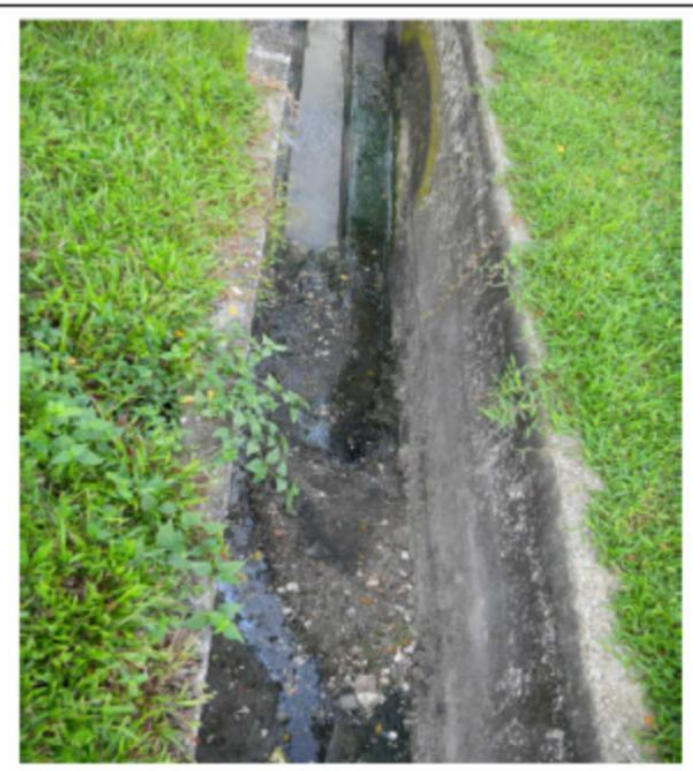

(a)

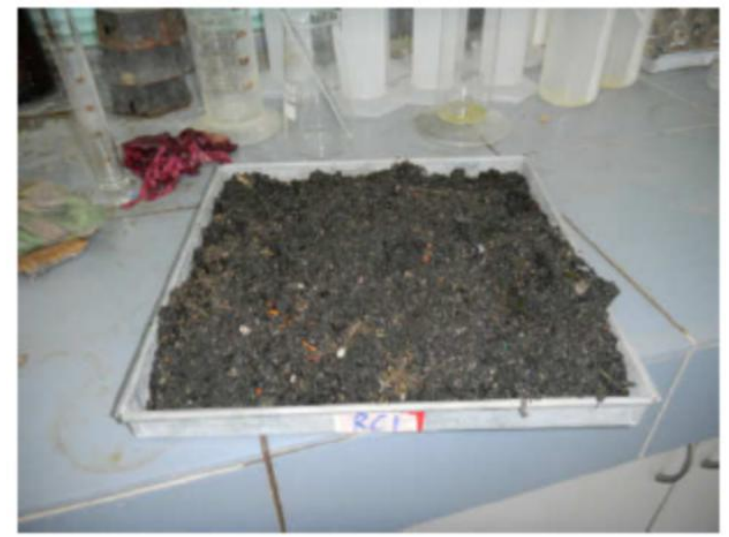

(c)

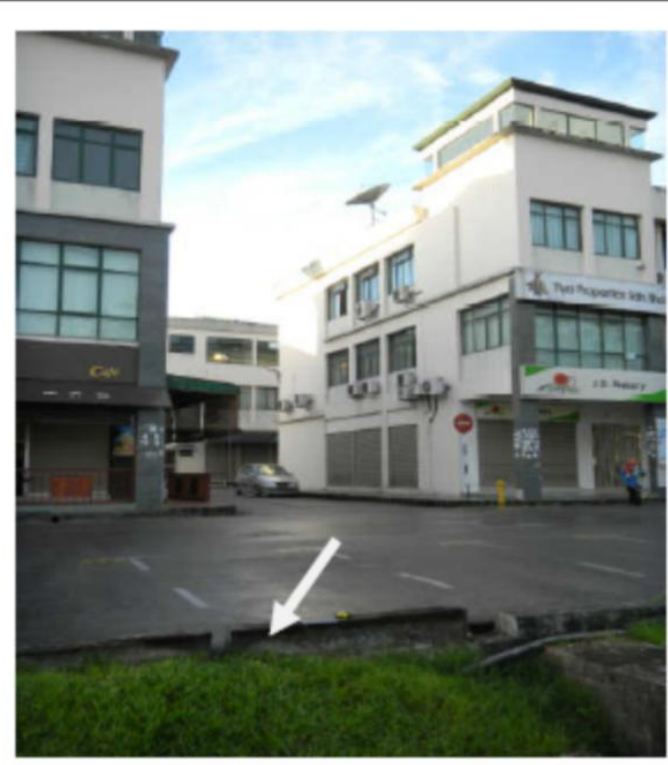

(b)

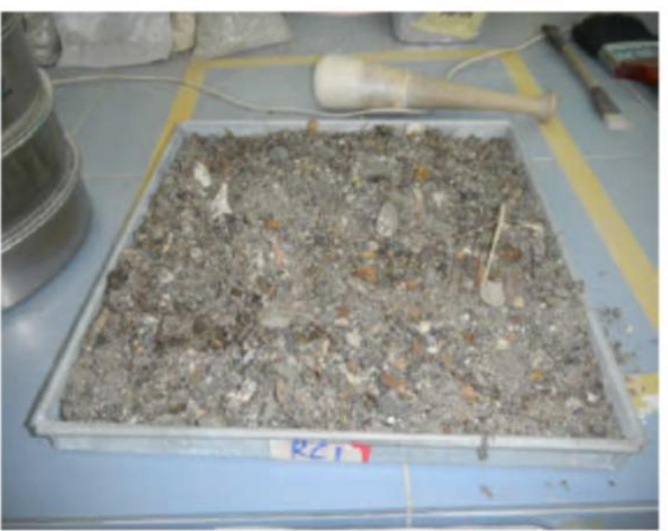

(d)

Figure 1. Sediment sampling at RH Plaza Commercial Centre in Kuching, Sarawak: (a) sediment deposition in monsoon concrete drain; (b) arrow showing the drain location for sampling; (c) the sediment sample before oven dry; (d) sediment sample after oven-dried but before removing the impurities.

The value of median diameter, $d_{50}$ was estimated from the cumulative grain size distribution while the value of mode diameter, $d_{\bmod e}$ was from the grain size histogram. Median diameter, $d_{50}$ is the size with a $50 \%$ passing on the cumulative grain size distribution curve while mode diameter, $d_{\text {mod } e}$ is the size having the largest percentage on the histogram of percentage retained against particle size. The mode frequency $f_{\bmod e}$ is the percentage value of mode for each sample. The mean diameter for the sample was calculated using the following expression:

$$
d_{m}=\frac{\sum \Delta_{i} d_{i}}{100}
$$


where $\Delta_{i}$ represents any portion of the percentages shown on the vertical axis of the cumulative grain size distribution curve and $d_{i}$ represents the mean value of the sizes established by the extreme values of the interval $\Delta_{i}$. The standard deviation $\sigma$ is given by:

$$
\sigma=\left[\frac{\sum_{i=1}^{j} f_{i}\left(d_{i}-d_{m}\right)^{2}}{\left(\sum_{i=1}^{j} f_{i}\right.}\right]^{1 / 2}
$$

where $d_{i}$ is the mean size of $i$ th class, $d_{m}$ is the mean size of the sample (see Equation 1), $f_{i}$ is the percentage of sample by weight of $i$ th class and $j$ is the total number of classes.

In order to choose which one is more stable and representative of the sediment distribution, the median, $d_{50}$; mode, $d_{\text {mode }}$ and mean, $d_{\text {mean }}$ were subjected to stability test. Stability test was performed using the ratio $d / \bar{d}$; where $\bar{d}$ is the arithmetic mean for the parameter (median, mode or mean), and is given in the following expression:

$$
\bar{d}=\frac{\left(\sum_{k=1}^{n} d_{k}\right)}{n}
$$

(Equation 3)

where $d_{k}$ is the parameter size of $k$ th sample number and $n$ is the total number of samples considered [9].

\section{Results and Analysis}

Results of the sieve analysis are summarized in Table 1 while Figure 2 shows the sediment particle size distribution curves for all the 15 locations. It was seen that all the 15 locations have unimodal grain size distribution. The major components for almost all the location was sand (except for Seremban), ranging from $41.6 \%$ to $85.9 \%$ with a mean for all the location of $72.2 \%$. Gravel constituent of about $10 \%$ to $58 \%$ with a mean of $24.7 \%$ for all the locations. Almost all the locations except Ipoh have silt and clay as the minor components with a range of $0.0 \%$ to $8.3 \%$ and a mean of $3.1 \%$. The standard deviation for the sediment particles size distribution for all the locations ranged from $0.96 \mathrm{~mm}$ to $4.18 \mathrm{~mm}$ with an average of $2.77 \mathrm{~mm}$. A similar case study on the deposition characteristics in urban drain for Kuching City, Malaysia also produced similar results where generally sand is the major component while silt and clay is the minor component [10]. 
Table 1 Sediment distribution characteristics for major urban areas in Malaysia

\begin{tabular}{|c|c|c|c|c|c|}
\hline \multirow{2}{*}{ Location } & Sample & \multicolumn{5}{|c|}{ Sediment Distribution } \\
& & \multicolumn{4}{|c|}{ Type } \\
\cline { 3 - 6 } & & Clay \& silt (\%) & Sand (\%) & Gravel (\%) & $\sigma(\mathrm{mm})$ \\
\hline Bandar Kangar & Unimodal & 6.5 & 73.5 & 20.0 & 1.98 \\
Alor Setar & Unimodal & 2.5 & 65.5 & 32.0 & 3.68 \\
Butterworth & Unimodal & 1.4 & 68.6 & 30.0 & 2.32 \\
Ipoh & Unimodal & 0.0 & 85.0 & 15.0 & 2.52 \\
Kuala Lumpur & Unimodal & 0.5 & 71.5 & 28.0 & 2.22 \\
Shah Alam & Unimodal & 0.8 & 64.2 & 35.0 & 2.85 \\
Seremban & Unimodal & 0.4 & 41.6 & 58.0 & 4.04 \\
Melaka & Unimodal & 3.7 & 73.3 & 23.0 & 2.96 \\
Johor Bahru & Unimodal & 7.1 & 82.9 & 10.0 & 0.96 \\
Kuantan & Unimodal & 4.1 & 84.9 & 11.0 & 2.58 \\
Kuala Terengganu & Unimodal & 3.1 & 85.9 & 11.0 & 2.33 \\
Kota Bahru & Unimodal & 8.3 & 70.7 & 21.0 & 2.09 \\
Kuching (Residential) & Unimodal & 0.9 & 69.1 & 30.0 & 4.18 \\
Kuching (Commercial) & Unimodal & 2.3 & 69.7 & 28.0 & 4.04 \\
Kuching (Industrial) & Unimodal & 4.9 & 76.1 & 19.0 & 2.77 \\
\hline Average & & $\mathbf{3 . 1}$ & $\mathbf{7 2 . 2}$ & $\mathbf{2 4 . 7}$ & $\mathbf{2 . 7 7}$ \\
\hline
\end{tabular}

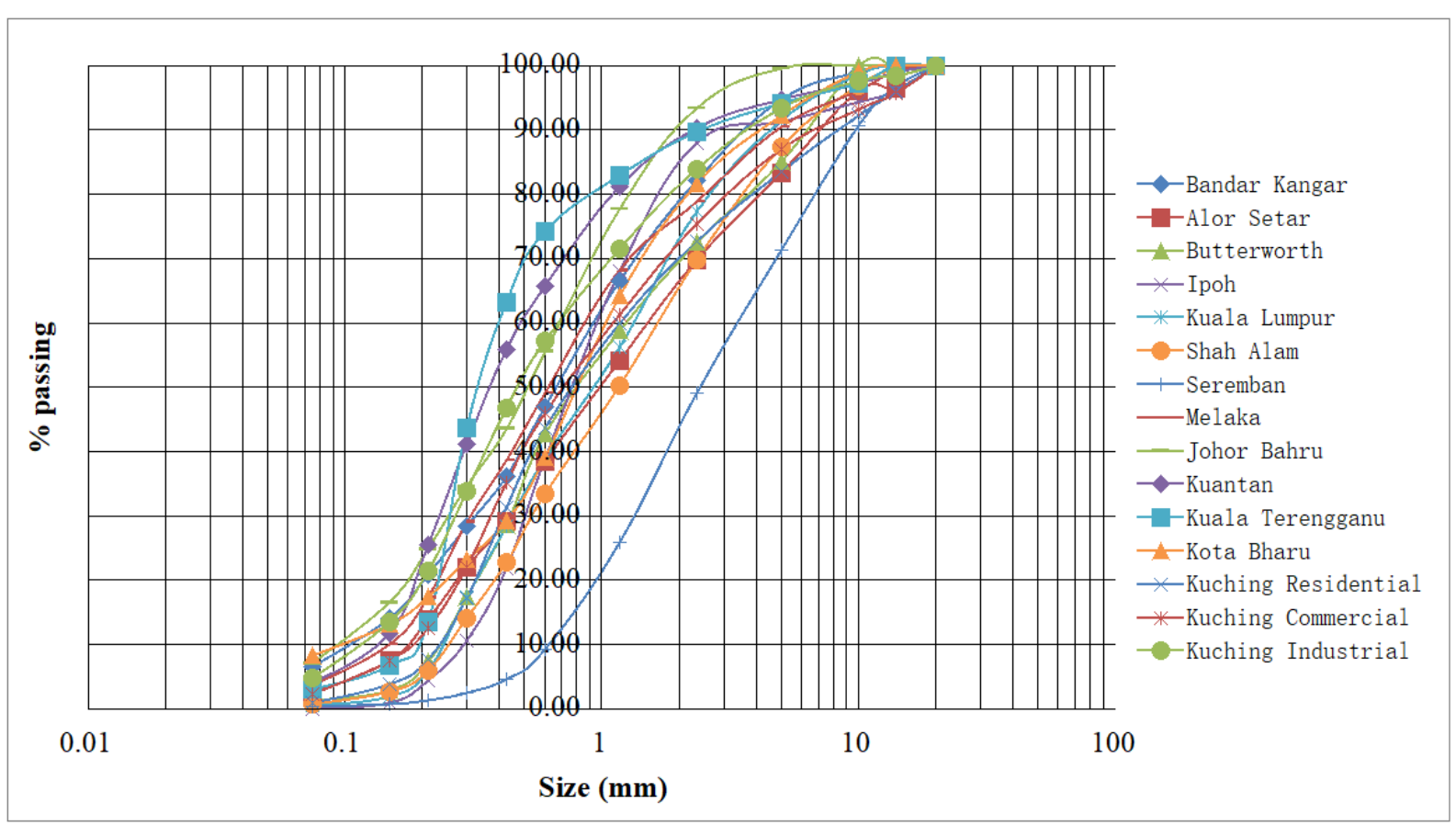

Figure 2. Sediment size distribution curves for major urban areas in Malaysia. 
To check the 'skewness' of the particle size distribution, a histogram of percentage retained against particle size was plotted for each of the locations like the one shown in Figure 3. Out of the 15 locations, 10 locations showed the characteristics of skewed to the coarser particle (skew to the right) where the mean have higher value than median, while median have higher value than mode. The 10 locations are Bandar Kangar, Butterworth, Ipoh, Shah Alam, Seremban, Kuantan, Kuala Terengganu, Kota Bahru, Kuching (residential) and Kuching (commercial). This has some similarity to the sediment samples from 5 residential areas in Kuwait where the samples skewed to the right [9]. This showed that most of the samples were not of normal distribution, thus using the median diameter, $d_{50}$ might not be a good representative of the sediment samples size. The rest of the locations namely Alor Setar, Kuala Lumpur, Johor Bahru and Kuching (industrial) did not showed a clear skewed distribution with the mean value higher than mode and mode higher than median. As for Melaka, it also did not showed a clear skewed distribution with the mean higher than mode; while median and mode have the same value.

Since most of the incipient formula developed is based on a single particle size due to the simplicity in the calculation procedure, it is important to determine the most appropriate size to represent the entire sediment deposit. Some literature suggested that the mode size; $d_{\bmod e}$ could be a better representative of the sediment deposit than the mean size; $d_{50}[8 ; 11]$. This is because mode is a more stable statistical parameter than mean and median. Mean, being the average of the particle size varies depending on the nature of the sediment data; while median may become sensitive to the shape of the data set distribution and often does not depict the typical outcome. Mode, on the other hand is less bias due to the nature of mode that always represent the highest percentage of particle by weight [9].

The histogram of percentage retained against particle size also showed the size with the highest percentage of particle retained or the mode. The mode size for the samples was ranging from $0.21 \mathrm{~mm}$ to $1.18 \mathrm{~mm}$ with an average of $0.70 \mathrm{~mm}$. An analysis on the frequency of mode percentile had showed that the mode has the highest frequency in the range of $15 \%$ to $20 \%$ (midpoint at $17.5 \%$ ) with 8 locations namely Bandar Kangar, Alor Setar, Butterworth, Shah Alam, Melaka, Kuantan, Kuching (residential) and Kuching (commercial) have mode in that range. Figure 4 shows the frequency histogram of the mode percentile for the sediment samples from the 15 locations. The average mode percentile is at $20.2 \%$ as showed in Table 2 . Table 2 also summarized the effective grain size for median, mean and mode of the samples. The median, $d_{50}$ for the samples was ranging from $0.35 \mathrm{~mm}$ to $2.4 \mathrm{~mm}$ with an average of 0.83 . The mean, $d_{\text {mean }}$ was ranging from $0.86 \mathrm{~mm}$ to $4.04 \mathrm{~mm}$ with an average of $1.91 \mathrm{~mm}$. Comparing the mode percentage (see Table 2) with the results from 5 residential areas in Kuwait [9], he mode range for the Malaysian major urban areas which was in the range of $14.4 \%$ to $30.2 \%$ actually falls within the range for the samples from Kuwait with the range of $11 \%$ to $33 \%$. In terms of mode grain size however, the mode size of Malaysian major urban areas is larger with an average of $0.7 \mathrm{~mm}$ compares with the mode size of Kuwait with an average of $0.3 \mathrm{~mm}$.

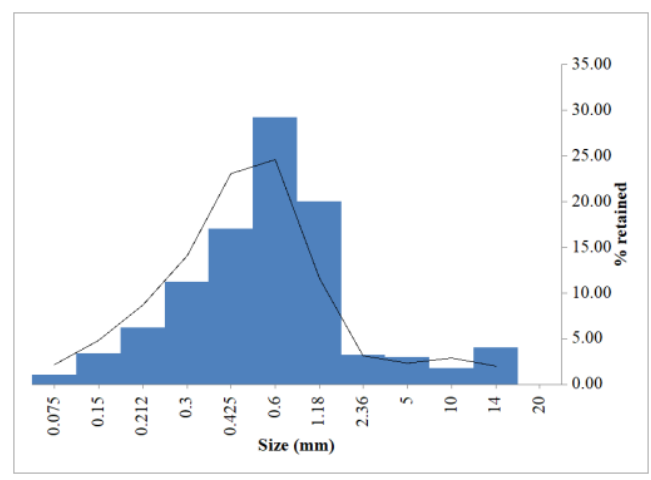


(a)

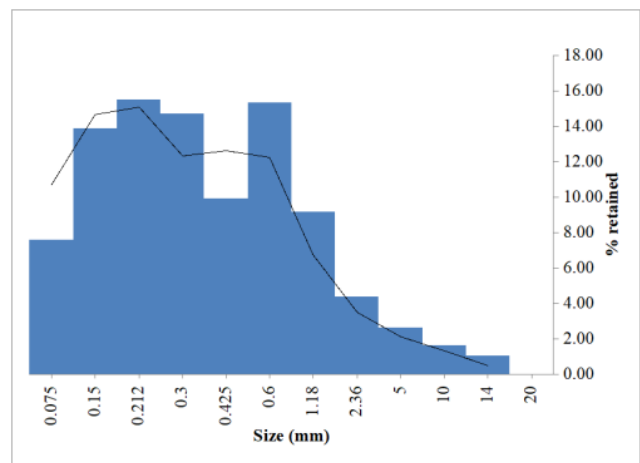

(b)

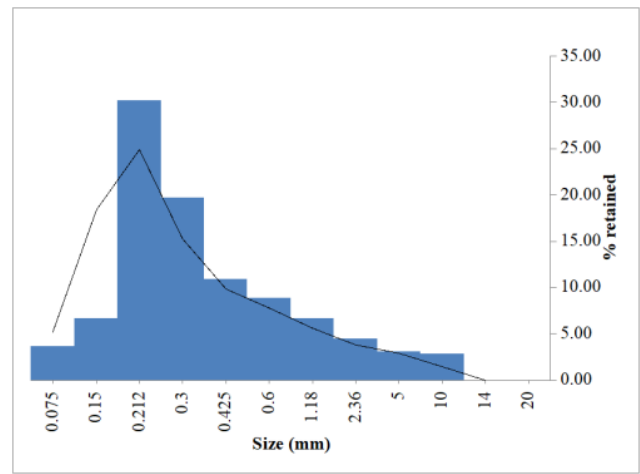

(c)

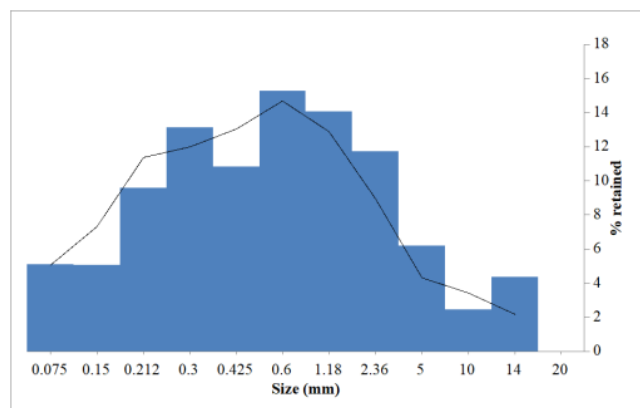

(d)

Figure 3. Histograms for sediment size distribution: (a) Ipoh; (b) Kuantan; (c) Kuala Terengganu; (d) Kuching (Commercial). 


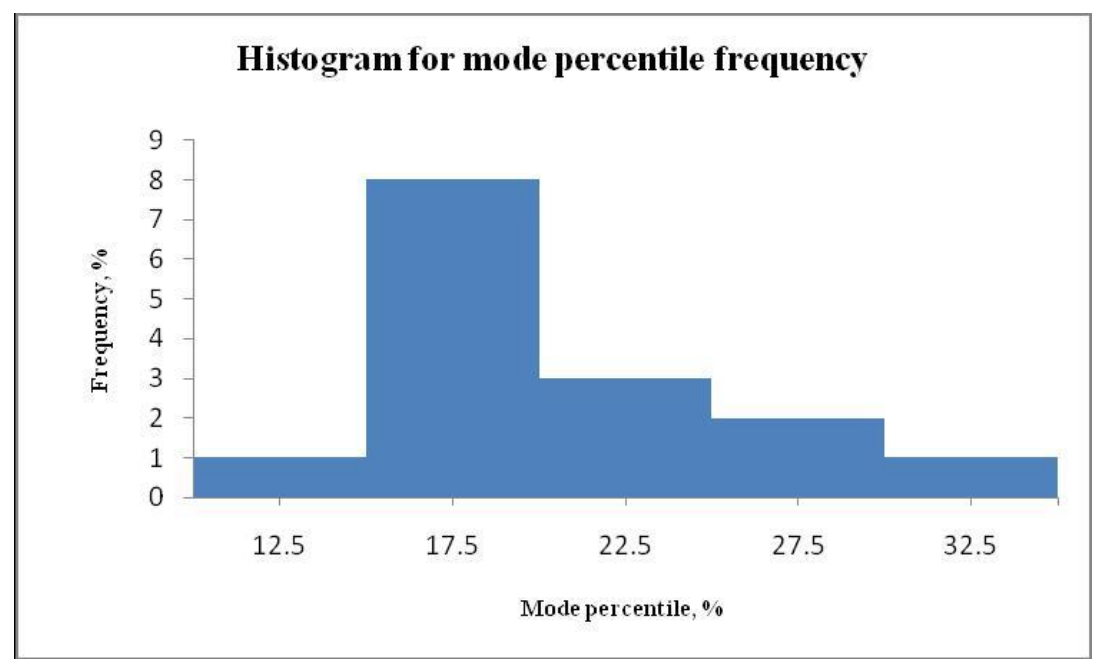

Figure 4. Histogram for mode percentile frequency.

Table 2 Effective sediment grain size for major urban areas in Malaysia

\begin{tabular}{|c|c|c|c|c|}
\hline \multirow{2}{*}{ Location } & \multicolumn{4}{|c|}{ Effective Grain Size } \\
\cline { 2 - 5 } & $\mathrm{d}_{50}(\mathrm{~mm})$ & $\mathrm{d}_{\text {mean }}(\mathrm{mm})$ & $\mathrm{d}_{\text {mode }}(\mathrm{mm})$ & $\begin{array}{c}\mathrm{f}_{\text {mode }} \\
(\%)\end{array}$ \\
\hline Bandar Kangar & 0.70 & 1.43 & 0.60 & 19.6 \\
Alor Setar & 1.00 & 2.55 & 1.18 & 15.8 \\
Butterworth & 0.85 & 2.01 & 0.60 & 16.0 \\
Ipoh & 0.80 & 1.21 & 0.60 & 29.2 \\
Kuala Lumpur & 0.90 & 1.81 & 1.18 & 21.0 \\
Shah Alam & 1.20 & 2.30 & 1.18 & 19.6 \\
Seremban & 2.40 & 4.04 & 1.18 & 23.2 \\
Melaka & 0.60 & 1.82 & 0.60 & 19.0 \\
Johor Bahru & 0.55 & 0.86 & 0.60 & 22.2 \\
Kuantan & 0.38 & 1.20 & 0.21 & 15.5 \\
Kuala Terengganu & 0.35 & 1.14 & 0.21 & 30.2 \\
Kota Bahru & 0.80 & 1.59 & 0.60 & 25.1 \\
Kuching (Residential) & 0.80 & 2.68 & 0.60 & 16.3 \\
Kuching (Commercial) & 0.70 & 2.43 & 0.60 & 15.3 \\
Kuching (Industrial) & 0.48 & 1.51 & 0.60 & 14.4 \\
\hline Average & $\mathbf{0 . 8 3}$ & $\mathbf{1 . 9 1}$ & $\mathbf{0 . 7 0}$ & $\mathbf{2 0 . 2}$ \\
\hline
\end{tabular}

To test the stability of the parameter (mode, mean and median) of the samples, the ratio of the parameter with the arithmetic mean of the parameter (see Equation 3) was calculated. A graph of ratio value for all parameters against the location sample number, $n$ was plotted and as shown in Figure 5 . From Figure 5, it was showed that mode have a smaller dispersion in terms of the parameter ratio if compares to the parameter ratio for mean and median. Mode has a parameter ratio range of 0.3 to 1.69 with a spread or dispersion of 1.39. Mean has a parameter ratio range of 0.45 to 2.12 with a spread of 1.67; while median has a parameter ratio range of 0.42 to 2.88 with a spread of 2.46 . 
Figure 5 shows that mode is more stable than mean and median due to the smaller dispersion value of parameter ratio $d / \bar{d}$. It means that the mode value for all the locations varies the least among each other and also with the average mode of the samples as compares to the value of mean and median. This suggest that if one is to choose a fixed percentile to represent the sediment particle sizes for Malaysian urban drains to be used in incipient motion formula, that percentage should be close to $20 \%$ or in other word, the effective representative grain size is $d_{20}$.

Though, statistically the mode with a representative grain size, $d_{20}$ is a better representative for the sediment particles in Malaysian urban drains than the median, $d_{50}$; there is much to be done when it comes to the application in the incipient motion equations. Further experimental works are needed to develop incipient motion equations based on $d_{20}$ and testing of the developed equations in the field.

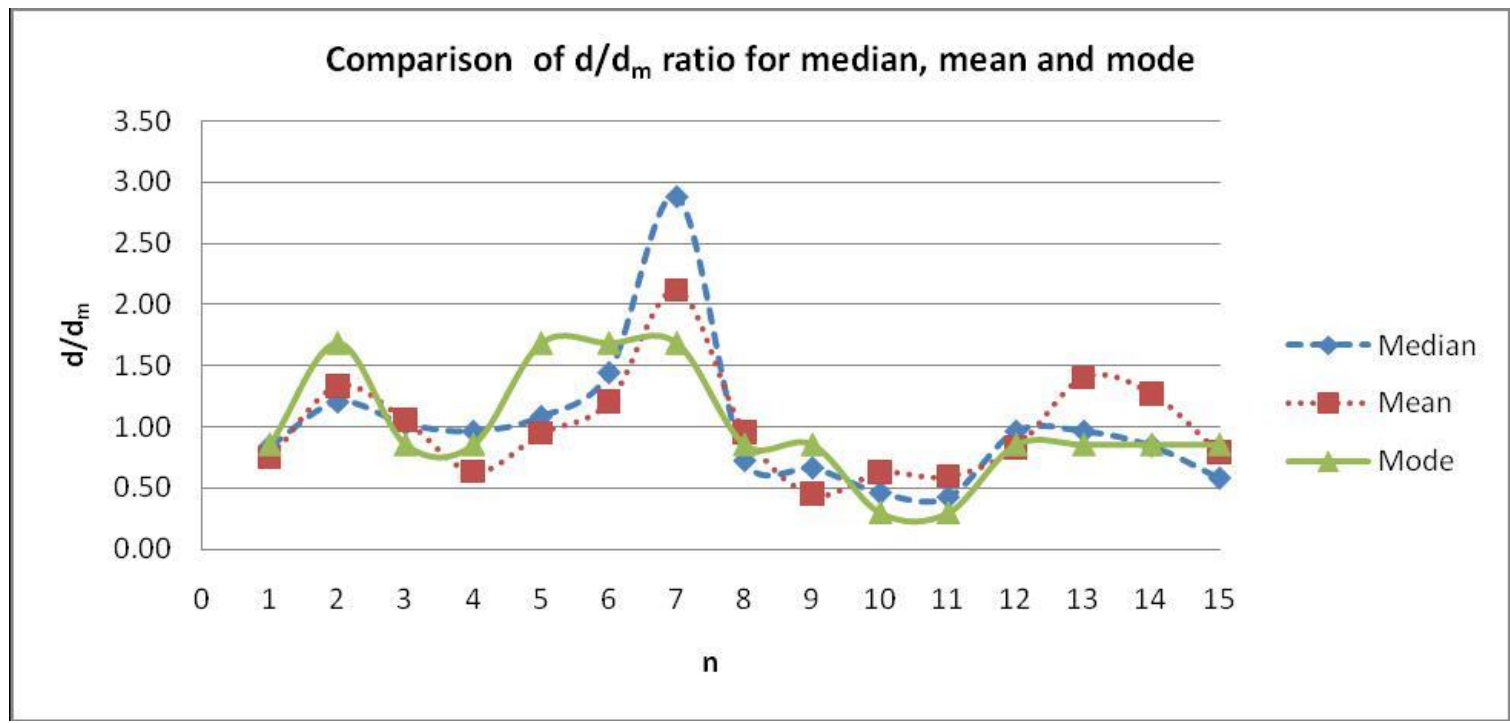

Figure 5. Comparison of the parameter ratio $d / \bar{d}$ calculated for the median, mean and mode particle sizes.

\section{Conclusions}

Sediment sampling and analysis from concrete drains of 15 urban locations in Malaysia had generally shown that sand was the major component (except for 1 location) with an average of $72.2 \%$, followed by gravel with average of $24.7 \%$ and silt and clay as the minor component with average of $3.1 \%$. Further analysis had also shown that most of the samples are not normally distributed with samples from 10 locations showing a clear skew to the right. Hence, the conventionally used median, $d_{50}$ as the effective grain size for the sediment size distribution might not be a good representative of the samples. The use of mode (in this case the $d_{20}$ grain size) has been suggested in this paper instead based on the statistical analysis and stability test to represent the grain size distribution for Malaysian urban areas. Further experimental and field works are required to quantify the suitability of mode as the representative grain size for sediment size distribution.

\section{Acknowledgements}

The author would like to thank Universiti Malaysia Sarawak for the financial support under the MyRA Special Grant Scheme (grant no. F02/SpGS/1542/2017). 


\section{References}

[1] Ab. Ghani, A., Salem, A.M., Abdullah, R., Yahaya, A.S. and Zakaria, N.A. (1999). Incipient Motion of Sediment Particles over Deposited Loose Beds in a Rectangular Channels, $8^{\text {th }}$ International Conference on Urban Storm Drainage, Sydney, Australia.

[2] El-Zaemey, A.K.S. (1991). Sediment Transport Over Deposited Beds in Sewers, Ph.D. Thesis, Department of Civil Engineering, University of Newcastle upon Tyne, England.

[3] Novak, P. and Nalluri, C. (1975). Sediment Transport in Smooth Fixed Bed Channels, Journal of the Hydraulics Division, Vol. 101(HY9), 1139 - 1154.

[4] Ojo, S.I.A. (1978). Study of Incipient Motion and Sediment Transport Over Fixed Beds, Ph.D. Thesis, Department od f Civil Engineering, University of Newcastle upon Tyne, England.

[5] Ab. Ghani, A., Zakaria, N.A. and Kassim, M. (2008). Sediment Deposition in a Rigid Monsoon Drain, International Journal of River Basin Management, Vol. 6, No. 1, 23 - 30.

[6] Bunte, K. and Abt, S.R. (2001), Sampling Surface and Subsurface Particle-Size Distribution in Wadable Gravel- and Cobble-bed Streams for Analyses is Sediment Transport, Hydraulics, and Streambed Monitoring, Technical Rep. No. RMRS-GTR-74, U.S.D.A. Forest Service, Rocky Mountain Research Station, Fort Collins, Colo.

[7] Kondolf, G.M. and Wolman, M.G. (1993). The Sizes of Salmonid Spawning Gravels, Water Resources Research, Vol. 29, No. 7, 2275-2285.

[8] Almedeij, J. and Diplas, P. (2003). Bedload Transport in Gravel-Bed Streams with Unimodal Sediment, Journal of Hydraulic Engineering, Vol. 129, No. 11, 896-904.

[9] Almedeij, J., Ahmad, E. and Alhumoud, J. (2010). Representative Particle Size of Sediment in Storm Sewer Inlets, American Journal of Environmental Sciences, Vol. 6, No. 4, 316-323.

[10] Bong, C.H.J., Lau, T.L. And Ab. Ghani, A. (2014). Sediment Size and Deposition Characteristics in Malaysian Urban Concrete Drains - A Case Study of Kuching City, Urban Water Journal, Vol. 11, No 1, 74-89.

[11] Almedeij, J., Diplas, P. And Al-Ruwaih, F. (2006). Approach to Separate Sand from Gravel for Bed-load Transport Calculations in Streams with Bimodal Sediment, Journal of Hydraulic Engineering, Vol. 132, No. $11,1176-1185$. 